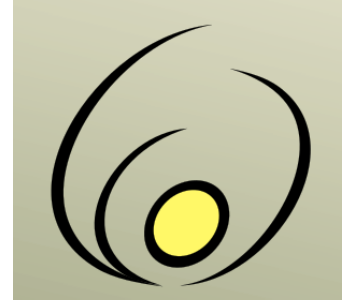

Fórum de Pró-Reitores de Extensão das Instituições Públicas de Educação Superior Brasileiras
Revista Brasileira de Extensão Universitária

v. 11, n. 2, p. $237-246$, mai.-ago. 2020

e-ISSN 2358-0399

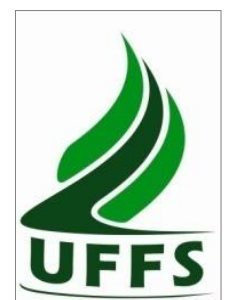

Content shared under Creative Commons Attribution 4.0 Licence CC-BY

\title{
Retratos de uma ação extensionista de química para meninas da educação básica
}

Anny Carolina de Oliveira $^{1}$, Janaina Farias de Ornellas ${ }^{2}$

Resumo: Este artigo tem como objetivo socializar uma oficina temática de Química e Higiene que fez parte do projeto de extensão Pesquise como uma garota. Este projeto tem o intuito de refletir e discutir sobre o lugar das mulheres na ciência de maneira que seja possível perceber que elas também possuem competências para as áreas de Ciência, Tecnologia, Engenharia e Matemática que, historicamente, têm sido dominadas por figuras masculinas. Tal oficina foi realizada na Universidade, mais especificamente, no Laboratório de Química. Foi planejada tendo em vista a duração máxima de uma hora e meia, e contou com a participação de dezoito estudantes do Ensino Fundamental $\|$ da rede pública e privada. A oficina foi composta de quatro momentos: i) dialogar sobre as mulheres na ciência; ii) debater sobre a química do sabão e sabonete; iii) conhecer o laboratório de química e iv) produzir o sabonete líquido. Os resultados evidenciam que, apesar da limitação de tempo e contingenciamento financeiro para a realização da oficina temática, as inscritas se mostraram bastante participativas, manifestando empenho nas diferentes atividades propostas e nos constantes questionamentos levantados ao longo da ação. Por isso, acreditamos que a inserção de cientistas femininas no currículo escolar se faz pertinente não só pelo interesse das estudantes, mas também para promover o empoderamento feminino. Reafirmamos que atividades extensionistas são importantes para conscientizar que meninas também podem ocupar áreas da ciência e tecnologia, ainda que estes campos sejam majoritariamente masculinos, devido à construção patriarcal da sociedade.

Palavras-chave: Oficina Temática; Higiene; Mulheres Na Ciência

\section{Portraits of a chemistry extensionist action for girls in elementary education}

Abstract: This article aims to socialize a Chemistry and Hygiene Thematic workshop, which was part of the extension project Research like a girl. This project intends to reflect and discuss the place of women in society so that it is possible to notice that they also have competence for the Scientific, Technology, Engineering, and Mathematics areas, which have been historically dominated by men figures. The workshop was held at the University, more specifically, at the Chemistry Lab. It was planned to take one and a half-hour long and had the participation of eighteen students from public and private schools of elementary education. The workshop had four main moments: i) dialogue about women in science; ii) debate about the Chemistry aspects of soap; iii) get to know the Chemistry Lab and iv) production of liquid soap. The results showed that despite the time the limitation of time and financial resources for the implementation of the thematic workshop, the participants proved to be very participatory, expressing their commitment to the different activities proposed and to the constant questions raised during the workshop. Therefore, we believe that the insertion of female scientists in the school curriculum makes it pertinent not only by the interest of the female students but also to promote female empowerment. We reaffirm that extensionist activities are essential to raising awareness that girls can also occupy science and technology areas, although these areas are mainly male-dominated due to the society's patriarchal construction.
Originais recebidos em 06 de julho de 2020

Aceito para publicação em 07 de agosto de 2020

1 Licenciada em Química e mestra em Ensino de Ciências e Matemática pela Universidade Federal de Uberlândia - UFU. Membro do Grupo de Estudo e Pesquisa sobre Formação de Professores e Ensino de Ciências - FORPEC. oliveiraanny@live.com (autora para correspondência)

2 Licenciada em Química e Mestre em Educação pela Universidade Estadual Paulista - UNESP, doutora em ensino de Química pela Universidade de São Paulo - USP e professora da Universidade Federal do Triângulo Mineiro - UFTM, Uberaba-MG

Líder do Grupo de Estudo e Pesquisa sobre Formação de Professores e Ensino de Ciências - FORPEC.

janaina.ornellas@uftm.edu.br 


\section{Introdução}

Este artigo tem como objetivo socializar os resultados alcançados por uma atividade extensionista a respeito da presença e do papel da mulher na ciência, que fez parte do projeto intitulado "Pesquise como uma garota", desenvolvido com alunas do Ensino Fundamental II (EF II). Inicialmente, realizamos alguns apontamentos acerca da participação feminina na produção científica, bem como promovemos reflexões sobre a desigualdade de gênero nas diferentes áreas do saber. Em seguida, são apresentadas as diretrizes do referido projeto, que dá origem às discussões aqui realizadas. Posteriormente, descrevemos como foi estruturada a oficina e seus objetivos. Na sequência, apresentamos os resultados observados a partir da atividade realizada. Por fim, à guisa de conclusão, são feitas algumas considerações a respeito da oficina e como esta atividade foi observada pelas autoras.

\section{Um percurso histórico}

Chassot (2004) aponta que não só a ciência, mas quase toda produção intelectual é majoritariamente masculina, e explana o que chama de "tríplice ancestralidade" evidenciando aspectos de religiões que alicerçaram o papel subserviente da mulher ocidental. Ao analisar as vertentes grega, judaica e cristã, cita diferentes passagens marcadas por declarada misoginia. Na ancestralidade grega, após conflitos entre deuses e humanos, Zeus dá a Prometeu, uma mulher, Pandora, que deixa escapar, da caixa que traz consigo, todos os males do mundo. Na ancestralidade judaica, apresenta a ação de Eva que, por ser mais fraca e se render à tentação da serpente, é expulsa do paraíso junto a Adão. Além disso, é papel dos homens a aprendizagem do hebraico para estudo dos textos sagrados, enquanto que a mulher seria a responsável pelo lar e pelo mercado. Por fim, na ancestralidade cristã, é bastante conhecida a retórica de que, assim como Cristo é a cabeça da igreja, é o homem a cabeça da mulher, demonstrando a superioridade masculina.

Ao se pesquisar sobre os nomes laureados com o Prêmio Nobel, verificamos que poucas são as mulheres já agraciadas com essa honraria ${ }^{1}$. Do total de 213 pessoas que já receberam o Prêmio Nobel de Física, apenas 3 são mulheres. $O$ de Química já concedido à 184 pesquisadores, dentre os quais somente 5 foram figuras femininas. Do total de 219 laureados com o Prêmio Nobel de Fisiologia ou Medicina, 12 são mulheres. Na área de Ciências Econômicas apenas 2 são mulheres, dos 84 contemplados. O número de mulheres laureadas sofre uma ligeira, mas ainda tímida ascensão, nas categorias de Literatura e Paz, apresentando 15 e 17 mulheres premiadas, de um total de 116 e 134 pessoas comtempladas, respectivamente.

A Enquete Nacional de Percepção Pública da Ciência de 2015 (Velho, 2017) mostrou que os brasileiros têm, como principal fonte de informação sobre a área científica, a televisão, embora o acesso à internet para essa finalidade venha crescendo. Em pesquisa realizada sobre o perfil dos cientistas em duas emissoras de TV brasileiras (TV Globo e TV Record), constatou-se que "a quantidade de pesquisadoras identificadas (28 mulheres) foi quase quatro vezes menor do que a de homens (109) nas duas emissoras analisadas. Essa disparidade sugere uma predominância masculina na representação do cientista na TV brasileira" (Carvalho \& Massarani, 2017, p. 223). Os dados dessa pesquisa se tornam ainda mais delicados ao se pensar que, sendo a televisão a principal fonte de informação sobre ciência, a baixa frequência de aparição das mulheres como representantes da carreira científica pode levar a acreditar que esta é uma área em que apenas os homens têm capacidade para integrá-la.

De acordo com o Censo da Educação Superior do ano de 2017 (Instituto Nacional de Estudos e Pesquisas Educacionais Anísio Teixeira - INEP, 2019), dos 20 maiores cursos de graduação em número de matrículas, os que possuem maior público feminino são as graduações das áreas de educação e saúde, dentre elas: Pedagogia (92,5\%), Serviço Social (90,1\%), Nutrição (85,2\%), Enfermagem (84,0\%), Psicologia (80,5\%), 
Odontologia (72,2\%), Farmácia (71,9\%) e Fisioterapia (79,0\%). Por outro lado, o público masculino se faz notadamente mais presente em cursos das áreas de exatas, como Engenharia Mecânica (89,7\%), Engenharia Civil (69,5\%), Engenharia de Produção (65,0\%), dentre outros.

Os dados apontados pelo INEP reforçam a premissa de Marques (2020), que atesta que, embora mais mulheres tenham ingressado no ensino superior, algumas carreiras são notoriamente dominadas por homens. $\mathrm{O}$ autor cita o exemplo da Olimpíada Brasileira de Matemática nas Escolas Públicas do ano de 2018 em que, no Ensino Fundamental, apenas $30 \%$ dos medalhistas eram garotas, enquanto que na categoria de Ensino Médio, as meninas correspondiam a apenas $20 \%$ dos medalhistas. Marques aponta que a falta de exemplos femininos em áreas como a matemática acaba distanciando as meninas a se perceberem como profissionais de determinados campos, às vezes levando-as a acreditarem que não têm capacidade/inteligência para seguirem certas carreiras.

Carvalho e Gil-Pérez (2011) também abordam este assunto ao comentarem a importância de saber avaliar, dentre as necessidades formativas do professor de Ciências. Os autores mencionam um estudo de Spears (1984) que apresentou um mesmo exercício resolvido por alunos a um grupo de professores e pediu que avaliassem tal atividade. Implicitamente, no enunciado do exercício, estava descrito se a resolução havia sido feita por um aluno ou uma aluna. Spears constatou que, as resoluções de exercício supostamente resolvidas por alunas eram substancialmente menos valorizadas do que resoluções idênticas resolvidas por alunos. Isso sugere que, não só as avaliações são consideravelmente subjetivas, mas que, além disso,

[...] a avaliação constitui um instrumento que afeta decisivamente aquilo que pretende medir; dito de outra forma, nós, professores, não só nos enganamos ao qualificar (dando, por exemplo, pontuações mais baixas em matérias como Física a exercícios que acreditamos feitos por meninas), mas ainda contribuímos para que preconceitos - preconceitos estes de toda a sociedade - se transformem em realidade: as meninas acabam tendo resultados inferiores e atitudes mais negativas com relação à aprendizagem de Física que os meninos; [...] (Carvalho \& Gil-Pérez, 2011, p. 58).

Motivadas por esse panorama, socializamos a atividade extensionista realizada no segundo semestre de 2019, que empreendeu esforços para envolver meninas na discussão sobre as mulheres na carreira científica.

\section{O projeto "Pesquise como uma garota" como lócus de transformação desse cenário}

Em 1988, no Artigo 207 da Constituição Federativa do Brasil, a configuração do Ensino Superior Brasileiro enfatiza que o processo de ensino e aprendizagem, desenvolvido nesta etapa, deve ser pautado a partir da tríade formada por Ensino-Pesquisa-Extensão de forma indissociável, destinando às Universidades autonomia para planejar como se dará esse processo. Paula (2013) defende que a

Extensão universitária é o que permanente e sistematicamente convoca a universidade para o aprofundamento de seu papel como instituição comprometida com a transformação social, que aproxima a produção e a transmissão de conhecimento de seus efetivos destinatários, cuidando de corrigir, nesse processo, as interdições e bloqueios, que fazem com que seja assimétrica e desigual a apropriação social do conhecimento, das ciências, das tecnologias (Paula, 2013, p. 6).

Diversas atividades têm sido realizadas por instituições de ensino superior, buscando estreitar os laços entre a academia e a Educação Básica, seja para promover diálogos e compartilhar experiências sobre a rotina das pesquisas universitárias e o processo de construção do conhecimento científico (De Gobbi et al., 2020; Dorigo et al., 2020) ou ainda, para propiciar reflexões sobre os impactos causados pelas atividades extensionistas na formação inicial dos discentes envolvidos (Pereira \& Oliveira, 2019). 
Tendo em vista a necessidade de promover ações que possibilitem que meninas estabeleçam contato com diferentes áreas da ciência e tecnologia, a fim de buscar construir uma maior igualdade de gênero, tanto no ingresso ao ensino superior, quanto nas diferentes carreiras profissionais existentes, nos juntamos às organizadoras do projeto e colocamos em prática a oficina de química intitulada "Química e higiene", na

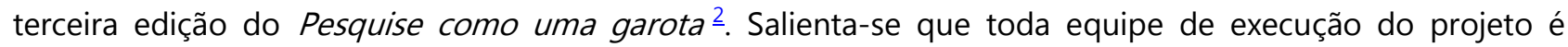
composta por mulheres (docentes, discentes e técnico-administrativo), objetivando que as meninas que participam do projeto possam se reconhecer nas diferentes identidades envolvidas na realização da ação.

O projeto promove diálogos entre a equipe de execução da ação com as alunas do EF II ( $6^{\circ}$ ao $9^{\circ}$ ano), de escolas públicas e privadas, sobre o papel das mulheres na ciência e as grandes contribuições já realizadas por algumas personalidades em diferentes áreas. O projeto está em sua terceira edição, e já contou com minicursos nas áreas de matemática, física, programação, engenharia, paleontologia, química, dentre outras. A premissa é de que, a partir das atividades extensionistas realizadas no Pesquise como uma garota, seja incentivada a reflexão e, se possível, desconstrução de alguns padrões sexistas ensinados por gerações, levando a ver a ciência e a produção científico-tecnológica como um lócus patriarcal.

Neste sentido, é relevante retratar as atividades realizadas, especificamente, na oficina "Química e Higiene", que foi elaborada/organizada pelas autoras com auxílio de graduandas do curso de Licenciatura em Química da UFTM.

\section{Metodologia}

\section{O planejamento da ação a partir da metodologia de oficinas temáticas}

A ação foi planejada de acordo com a proposição metodológica de oficinas temáticas de Marcondes (2008). A autora elenca uma série de características das oficinas temáticas como metodologia e, ancorados nesse referencial, acreditamos que a ação relatada se enquadra como uma oficina temática tendo em vista que, ainda que não tenha sido um tema emergido pelo grupo, se promoveu:

[i] Utilização da vivência dos alunos e dos fatos do dia-a-dia para organizar o conhecimento e promover aprendizagens. [ii] Abordagem de conteúdos da Química a partir de temas relevantes que permitam a contextualização do conhecimento. [iii] Estabelecimento de ligações entre a Química e outros campos de conhecimento necessários para se lidar com o tema em estudo. [iv] Participação ativa do estudante na elaboração de seu conhecimento (Marcondes, 2008, p. 68).

A oficina com base na temática escolhida, Química e Higiene, teve como objetivo aproximar as estudantes da ciência e mostrar que mulheres também podem ser cientistas. Tal oficina foi realizada na Universidade, mais especificamente, no Laboratório de Química. Foi planejada tendo em vista a duração máxima de uma hora e meia, e contou com a participação de dezoito estudantes do EF II.

Para tanto, iniciamos com uma breve apresentação das responsáveis por ministrarem a oficina e depois solicitamos às inscritas que respondessem um questionário inicial (disponível em Material Suplementar). Um questionário pode ser entendido como um instrumento de investigação composto por "um conjunto de questões que são submetidas a pessoas com o propósito de obter informações sobre conhecimentos, crenças, sentimentos, valores, interesses, expectativas, aspirações, temores, comportamento presente ou passado, etc" (Gil, 2008, p. 121). O questionário inicial continha nove perguntas (discursivas e de múltipla escolha) a fim de obter informações para caracterizar o perfil das participantes, averiguar se elas conheciam algum(a) cientista, além de compreender suas expectativas e o que as incentivaram a participarem da ação. 
Posteriormente, introduzimos o assunto a partir da problematização "A Química e a higiene: o que esses assuntos tem em comum?". Para isso, utilizamos recursos multimídia, mostrando algumas relações entre a ciência e a higiene e, após discutimos de que maneira podemos utilizar a química a nosso favor no cotidiano. Na sequência, realizamos a atividade "Mulheres na ciência", onde comentamos algumas personalidades femininas que contribuíram amplamente para o progresso e o desenvolvimento científico, não só na química (nas ciências exatas naturais), mas também em outras áreas (humanas, tecnológicas e da saúde). Em seguida, alguns materiais e equipamentos do laboratório foram apresentados para que as meninas pudessem se familiarizar com o ambiente em que estavam.

A fim de propiciar um momento lúdico com as participantes, realizamos a dinâmica intitulada "Destinos compartilhados". Para esse momento, recorremos à obra "As cientistas: 50 mulheres que mudaram o mundo", de Rachel Ignotofsky (2017), e confeccionamos cartões com fotos e biografia de 50 mulheres que foram pioneiras em suas pesquisas e realizaram grandes feitos nas áreas de ciência, tecnologia, engenharia e matemática (STEM). Estes cartões foram afixados previamente embaixo das bancadas das participantes e serviram de estímulo para elas e para o desenvolvimento da oficina. A ideia dessa atividade foi propiciar que as estudantes conhecessem mulheres que, na maioria das vezes, não são reconhecidas no currículo escolar, mas que realizaram estudos importantes.

Inspiradas pela dinâmica anterior, as meninas prosseguiram com a prática de produção de sabonete líquido, utilizando materiais de laboratório como: béquer, bastão de vidro, pisseta, proveta, dentre outros.

Ao fim da oficina, as participantes responderam um novo questionário, com sete perguntas que versavam sobre: qual atividade elas mais se identificaram; qual a contribuição da oficina para os conhecimentos de ciências/química; se com a realização da oficina elas conseguiriam citar nomes de mulheres cientistas; qual das atividades desenvolvidas na oficina elas gostariam de realizar com mais frequência na escola e avaliação da oficina. Tais perguntas permitiram que as participantes externalizassem suas percepções e avaliassem as atividades realizadas.

Vale ressaltar que os sabonetes líquidos produzidos, assim como os cartões das cientistas, foram levados por elas, pois o objetivo disso era aproximá-las da ciência, uma vez que tiveram espaço de fala, e sua autonomia respeitada, nas mais diferentes atividades da ação. Além disso, pretendíamos motivá-las a dialogarem com os familiares sobre o que realizaram durante a oficina.

A perspectiva metodológica deste retrato insere-se no campo das pesquisas de abordagem qualitativa, que pode ser entendida como uma atividade que posiciona o observador no mundo, assumindo certo grau de subjetividade e valorizando fortemente processos indutivos na busca de tendências (Denzin \& Lincoln, 1997). Após leitura minuciosa dos questionários, as respostas foram agrupadas de acordo com suas semelhanças. Para preservar o anonimato, cada questionário foi designado por um código que contém a abreviação da palavra participante $(P)$ seguido de um número $(1,2, \ldots)$, assim os códigos são $P 1, P 2, P 3 \ldots$ sucessivamente. A partir disso, apresentamos os resultados e organizamos em dois blocos: o primeiro, referente ao questionário inicial e o segundo, sobre o questionário final (ver Material Suplementar).

\section{Resultados e Discussão}

\section{Percepções advindas da leitura e análise do questionário inicial}

Das dezoito inscritas na oficina "Química e Higiene", seis possuem 12 anos de idade, quatro delas tem 14 anos, três indicaram ter 13 e 11 anos e apenas duas possuem 15 anos. A respeito de que ano do EF as meninas estavam matriculadas, sete sinalizaram estar no $6^{\circ}$ ano, cinco delas no $9^{\circ}$ ano, quatro meninas cursavam o $8^{\circ}$ 
ano e apenas duas $07^{\circ}$ ano. Buscamos conhecer ainda de que rede de ensino as participantes eram provenientes. Observamos que das 18 estudantes, nove eram da Rede Pública de Ensino e nove da rede privada.

Ao serem questionadas se conheciam algum(a) cientista, cinco delas disseram que não, e treze afirmaram conhecer. Pedimos, então, para que citassem um nome de cientista e algumas inscritas foram além, mencionando mais de um nome, como apresentamos na Figura 1, por isso a somatória de respostas para essa questão, assim como para perguntas apresentadas posteriormente, superam o total de inscritas na oficina, ultrapassando, em diversos momentos, o total de 18 respostas.

Observamos que, do total de dez cientistas mencionados, apenas três são figuras femininas, sendo a física Marie Curie, a cientista mulher mais citada por elas na oficina, com um total de cinco menções. Esse resultado corrobora a afirmativa de Chassot (2004) de que "parece que usualmente não se valorizam significativamente as contribuições femininas. Marie Curie continua sendo quase a única cientista citada nas aulas" (p. 22). Essa carência de referência de mulheres na ciência pode levar ao entendimento das alunas da Educação Básica de que a carreira científica não é um campo profissional que possa ser habitado por mulheres, como discutido anteriormente.

Além de Curie, outras duas cientistas foram mencionadas pelas participantes, sendo a Ana Rita e a Kelly, professoras que ministraram a oficina de Nutrição do projeto Pesquise como uma garota nessa mesma edição, no período matutino. Isso evidencia, de certa forma, que ações como essa podem ampliar a percepção das garotas a respeito da participação feminina na ciência.

Ao questionarmos o motivo pelo qual elas se inscreveram na oficina, as justificativas foram diversas. De maneira consonante, o motivo confirmado por dez garotas era de que elas tinham interesse sobre o assunto e viram no projeto a oportunidade de saberem ainda mais, como podemos observar em P3, ao afirmar "por que me interesso muito sobre e gosto de conhecer novas coisas para mudar minha visão (...) quero um dia contribuir para a ciência", em P8, "por que eu achei interessante e gosto bastante de ciências", e quanto à P18: "por que eu amo ciências e química".

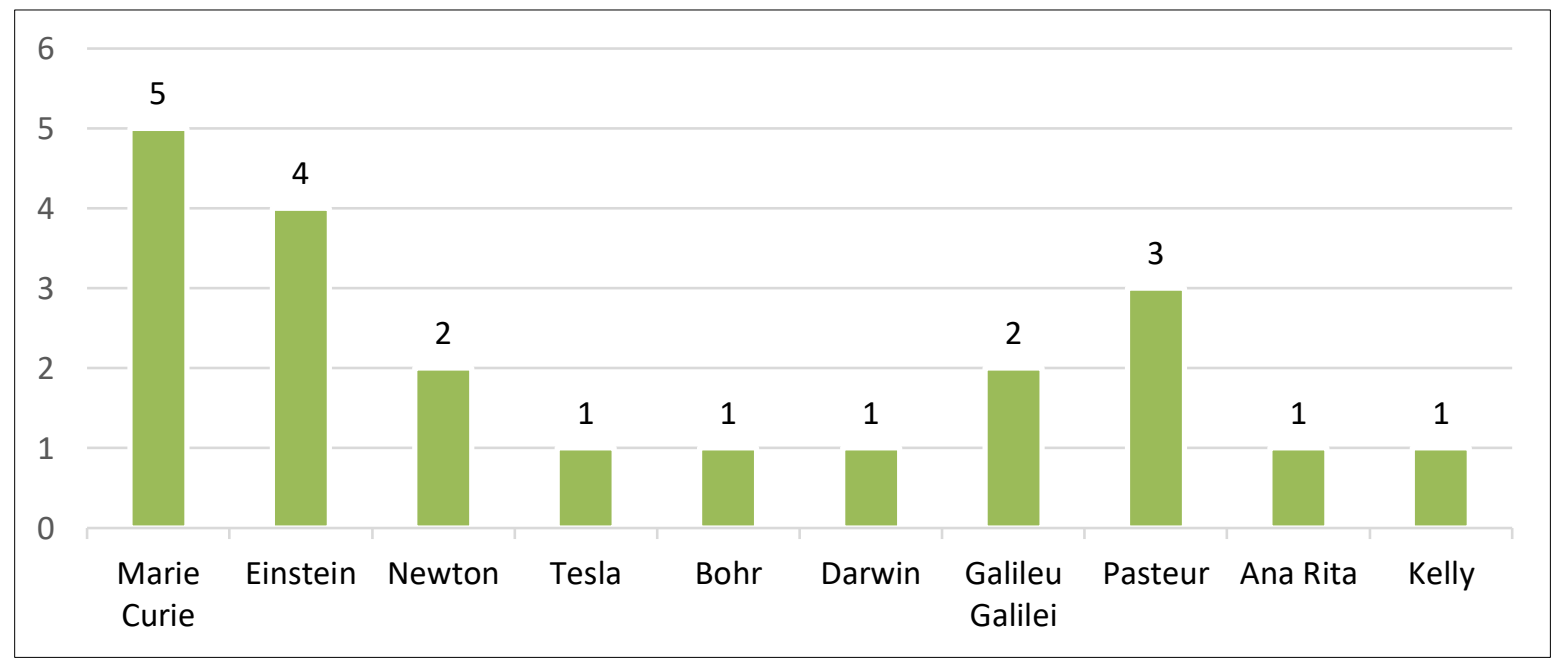

Figura 1. Personalidades da ciência citadas pelas participantes da oficina temática.

Fonte: As autoras (2020). 
Além disso, duas participantes atestaram que foram motivadas a participar da ação não só pelo interesse no campo da ciência, mas também por dar visibilidade às mulheres na área, como indica P14, ao dizer que "fui convidada pelo colégio (...) para comparecer ao projeto e me interessei pela proposta já que enaltece as mulheres e agregaria algo em meu aprendizado" e por P15, que afirmou que "fui convidada pelo colégio e achei uma proposta interessante, pois incentiva garotas a participar na ciência e a desenvolverem um senso feminista". Cinco estudantes atestaram participar do projeto apenas por orientação da direção escolar.

Duas meninas declararam que o interesse por atividades experimentais as levou a se inscreverem na oficina, como mostra P10: "eu me inscrevi porque sempre gostei de experimentos", e P12: "eu sempre gostei de ver as experiências na TV". A utilização de atividades práticas pode ser um interessante caminho para se estreitar o elo entre motivação e aprendizagem uma vez que, com um maior envolvimento dos alunos na realização das atividades, mais evoluções conceituais podem ocorrer (Santos \& Nagashima, 2017).

A estudante P2 explicou que a sua inscrição na oficina foi motivada "para aprender a como ser uma cientista". Essa afirmação demonstra que, ainda que seja de maneira tímida, as meninas também conseguem se visualizar na carreira científica, assumindo que, assim como os homens, as mulheres também possuem capacidade para ocupar esses espaços.

Também perguntamos quais as expectativas das meninas sobre a oficina de química. Nove esperavam realizar atividades experimentais, seis delas queriam compreender mais sobre a importância da ciência, duas almejaram que fosse um espaço de diálogo, três previam que seria uma atividade interessante, e duas indicaram que esperavam fazer novas amizades.

\section{Leitura e análise do questionário final: impactos da oficina temática}

A primeira questão do questionário final teve como objetivo conhecer qual das atividades realizadas durante a oficina as estudantes mais se identificaram. A produção do sabonete líquido foi assinalada por todas as dezoito estudantes como atividade que mais chamou atenção na oficina. A opção de conhecer mais sobre as cientistas foi indicada por sete estudantes, enquanto que a oportunidade de conhecer um laboratório foi apontada por seis delas. Por último, a relação entre química e higiene foi evidenciada por apenas cinco participantes.

Ademais, perguntamos quais das ações realizadas durante a oficina de extensão elas gostariam que fossem mais frequentes no ambiente escolar. Assim como observado na questão anterior, dezesseis apontaram que as atividades de laboratório poderiam ser mais presentes no cotidiano escolar. A abordagem de mulheres e suas contribuições na ciência foram apontadas por oito garotas, enquanto que curiosidades sobre a ciência foi um item mencionado apenas por seis meninas.

Esses resultados vão ao encontro do caráter motivador que as atividades experimentais apresentam, conforme citado por diversos pesquisadores da área (Santos \& Nagashima, 2017; Moraes \& Taziri, 2019). Entendemos que, ainda que a motivação despertada por essas atividades seja um ponto recorrente junto a estudantes e professores, em defesa dessa prática, a experimentação no contexto do ensino de Ciências/Química deve superar esta justificativa (Hodson, 1994). Obviamente, em determinados cenários, as atividades práticas objetivam envolver os sentidos das pessoas que as visualizam, promovendo um maior entusiasmo, como no caso de feiras de ciências, por exemplo. Para além dessa situação, outras justificativas também são elencadas para que as atividades experimentais possam ser utilizadas nos processos de ensino e aprendizagem (Hodson, 1994; Silva et al., 2020). 
Os depoimentos demonstram ainda a necessidade de que, durante as aulas de Ciências da Natureza, os professores deem cada vez mais abertura às figuras femininas que trouxeram suas contribuições para as mais diversas áreas da ciência.

Essas ações podem propiciar um maior engajamento feminino na ciência tendo em vista que, ao serem questionadas se a oficina temática despertou o interesse das participantes pela ciência, quinze delas responderam que "muito", duas assinalaram "não" e apenas uma afirmou ter contribuído "pouco" para promover o interesse pela área. Ainda foi perguntado se, após a atividade extensionista, elas conseguiriam citar o nome de mulheres cientistas. Das dezoito participantes, três atestaram que "não" e quinze afirmaram que "sim". Ainda que no questionário final não tenha sido solicitado que as participantes citassem um nome de cientista, é possível inferir que o aumento de respostas afirmativas para essa questão, saltando de cinco menções no questionário inicial para um total de quinze no final, é resultado da participação das meninas na oficina temática, uma vez que, após terem um maior contato com figuras femininas da área de STEM, as garotas se mostraram mais confortáveis para afirmar que conseguiam citar tais personalidades, caso fosse necessário. Uma amostra disso é o que se observou no espaço de comentários que, sem intuito nenhum de retomar nomes de cientistas, houve uma participante que o fez de maneira independente.

Por fim, buscamos compreender como as participantes avaliaram a oficina temática Química e Higiene e se as expectativas delas tinham sido alcançadas. Dezesseis estudantes consideraram a oficina como excelente e duas atestaram que foi ótima. Catorze indicaram que a oficina superou as suas expectativas e quatro tiveram suas expectativas atendidas. Também reservamos um espaço opcional no questionário final para que as participantes deixassem comentários/sugestões, dentre os quais destacamos três eixos:

1) O interesse pela área da ciência:

P03 "Eu amei tudo, as professoras, as experiências, a aula e tudo. Vocês me ajudaram a despertar meu conhecimento";

P15 "Gostei muitíssimo de ter essa oportunidade. Todas as professoras e alunas foram atenciosas e a oficina me despertou interesse em ciências";

2) A satisfação em produzir seu próprio sabonete líquido e conhecer mais sobre algumas cientistas:

P08 "Gostei muito de fazer um sabonete e de saber sobre as cientistas";

P11 "Gostei de fazer sabão líquido";

3) O feedback positivo para a continuação de novas edições do projeto Pesquise como uma garota:

P13 "Gostei muito de poder participar do projeto. Todas as alunas e professoras foram muito atenciosas e explicaram muito bem a mensagem a ser transmitida. Pretendo participar de outros projetos com esse tema";

P18 "Foi incrível, continuem sempre fazendo essa oficina".

P04 "Amei estar aqui e foi algo que guardarei minha vida toda";

Além de todos esses relatos, umas das participantes fez de suas as palavras da física austríaca Lise Meitner, a quem ela teve a oportunidade de conhecer parte da biografia através da dinâmica "destinos compartilhados", desenvolvida durante a ação extensionista. Para tanto, P01 deixou para o grupo de professoras a seguinte mensagem "a vida não precisa ser fácil, desde que não tenha sido vazia. Aprendi hoje com a Lise Meitner". 


\section{Considerações finais}

A atividade extensionista aqui relatada evidencia o quanto se faz necessário abrir espaço para promover discussões sobre a presença e o percurso das mulheres na ciência. Ainda que muitos estudiosos já abordem a não neutralidade científica, é preciso realizar ações que desconstruam a imagem do processo científico como atividade realizada apenas por homens, brancos e pertencentes a elites. Incluir as mulheres no campo científico não se justifica apenas por ser mais ética e moralmente correto, mas porque "ampliar o debate sobre a participação de mulheres na ciência significa também pensar numa ciência diferente, inspirada e renovada por experiências de vida historicamente excluídas da produção científica e tecnológica" (Brito et al., 2015, p. 39). Dessa forma, o campo científico não só precisa como deve ser ambientado pela mesma diversidade que encontramos na sociedade contemporânea. Para tanto, desde os anos iniciais da Educação Básica, é preciso que o corpo pedagógico escolar juntamente com seus professores promovam ações que contemplem a participação feminina nas diversas áreas da ciência, tecnologia, engenharias e matemática, pois, só assim, será possível promover uma maior equidade nas escolhas de meninos e meninas para os diferentes campos profissionais.

Acreditamos que esta ação extensionista possa estimular docentes, das instituições de ensino superior e da Educação Básica, a olharem com mais cuidado para a participação e o interesse das garotas/mulheres sobre a ciência. Afinal, ciência é, também, lugar de mulher.

\section{Agradecimentos}

Ao projeto, às participantes e às alunas da graduação.

\section{Contribuição de cada autor}

As autoras A. C. O. e J. F. O. planejaram as atividades; A. C. O. e J. F. O. desenvolveram com o auxílio de duas licenciandas do curso a ação extensionista; A. C. O. e J. F. O. estruturaram o referido artigo e revisaram o manuscrito final. Diante disso, solicitamos que a primeira autoria seja compartilhada entre esses autores.

\section{Notas}

${ }^{1}$ Dados disponíveis no site The Nobel Prize, https://www.nobelprize.org/.

${ }^{2}$ Projeto cadastrado sob protocolo número 331716.1589.287684.25042019 no Sistema de Informação e Gestão de Projetos ( http://sigproj.ufrj.br/ ).

\section{Referências}

Brito, C., Pavani, D., \& Lima Jr., P. (2015). Meninas na ciência: Atraindo jovens mulheres para carreiras de ciência e tecnologia. Gênero, 16(1), 33-50.

Carvalho, A. M. P. de, \& Gil-Pérez, D. (2011). Formação de professores de ciências. 10. Ed. São Paulo: Cortez.

Carvalho, V. B. de, \& Massarani, L. (2017). Homens e mulheres cientistas: Questões de gênero nas duas principais emissoras televisivas do Brasil. Intercom: Revista Brasileira de Ciências Da Comunicação, 40(1), $213-232$.

Chassot, A. (2004). A ciência é masculina? É, sim senhora!... Contexto e Educação, 19(71-72), 9-28.

De Gobbi, J. I. F., Kiss, A. C. I., \& Nishida, S. M. (2020). Semana de conscientização sobre o cérebro em Botucatu: Interação entre a universidade e o ensino fundamental. Revista Brasileira de Extensão Universitária, 11(1), 87-95. 
Denzin, N. K., \& Lincoln, Y. S. (2006). A disciplina e a prática da pesquisa qualitativa. In N. K. Denzin, \& Y. S. Lincoln (Orgs.), O planejamento da pesquisa qualitativa - teorias e abordagens. (pp. 15-42). Porto Alegre: Artmed.

Dorigo, A. S., Anjos, A., Marcato, A. C. C., Pires, D., Gonçalves, L. R., Anholeto, L. A., ... \& Mello, D. C. C. (2020). Projeto Primeiros Passos na Ciência: Rompendo barreiras sociais e estreitando laços entre a comunidade acadêmica e o Ensino Médio público. Revista Brasileira de Extensão Universitária, 11(1), 47-59.

Gil, A. C. (2008). Métodos e técnicas de pesquisa social. 6. ed. São Paulo: Atlas.

Hodson, D. (1994). Hacia un enfoque más crítico del trabajo de laboratorio. Ensenãnza de Las Ciencias, 12(3), $299-313$. Ignotofsky, R. (2017). As cientistas: 50 mulheres que mudaram o mundo. São Paulo: Edgar Blucher.

Instituto Nacional de Estudos e Pesquisas Educacionais Anísio Teixeira- INEP (2019). Resumo Técnico do Censo da Educação Superior 2017. Brasília: Instituto Nacional de Estudos e Pesquisas Educacionais Anísio Teixeira. Recuperado de: $\quad$ http://portal.inep.gov.br/documents/186968/484154/Resumo+T\%C3\%A9cnico+Censo+da+Educa\%C3\%A7\%C3 \%A3o+Superior+2017/ce993bae-3502-4098-a9aa-39b607d20161?version=1.0\&download=true

Marcondes, M. E. R. (2008). Proposições metodológicas para o ensino de química: Oficinas temáticas para a aprendizagem da ciência e o desenvolvimento da cidadania. Em Extensão, 7(1), 67-77.

Marques, F. (2020) A desigualdade escondida no equilíbrio: mulheres conquistam espaço na carreira científica no brasil, mas obstáculos no acesso a algumas áreas são desafio. Revista FAPESP (São Paulo) 1( 289), 26-31, Recuperado de: https://revistapesquisa.fapesp.br/a-desigualdade-escondida-no-equilibrio/

Moraes, V. R. A., \& Taziri, J. (2019). A motivação e o engajamento de alunos em uma atividade na abordagem do ensino de ciências por investigação. Investigações em Ensino de Ciências, 24(2), 72-89.

Paula, J. A. de (2013). A extensão universitária: História, conceito e propostas. Interfaces - Revista de Extensão, 1(1), 523.

Pereira, A. D. S., \& Oliveira, A. M. de. (2019). a Experiência extensionista no estágio supervisionado de química: o projeto de integração escolar. Revista Brasileira de Extensão Universitária, 10(3), 131-139.

Santos, D. M., \& Nagashima, L. A. (2017). Potencialidades das atividades experimentais no ensino de química. Revista de Ensino de Ciências e Matemática, 8(3), 94-108.

Silva, D. da, Couto, C. B. D., Strieder, D. M., \& Malacarne, V. (2020). A produção científica sobre experimentação no ensino de ciências: Objetivos e características. Revista Ciência e Desenvolvimento, 13(2), 323-342.

Spears, M. G. (1984). Sex bias in science teacher's ratings of work and pupil characteristics. European Journal of Science Education, 6(4), 369-377.

Velho, R. (2017). A ciência e a tecnologia no olhar dos brasileiros: Percepção pública da C\&T no Brasil 2015. Ciência e Cultura 69(4), 10-13.

\footnotetext{
$* * *$

Como citar este artigo:

Oliveira, A C. de \& Ornellas, J. F. de (2020). Retratos de uma ação extensionista de química para meninas da educação básica. Revista Brasileira de Extensão Universitária, 11(2), 237-246. https://periodicos.uffs.edu.br/index.php/ RBEU/article/ view/11591/pdf
} 